\title{
Piperazine based Zirconium Oxy-Chloride (PzZrOCl) single crystal: A Third Order Nonlinear Optical material for Opto-electronic Device Applications
}

Mullai RU ( $\sim$ mullairu@gmail.com )

Government Arts College https://orcid.org/0000-0001-7378-4916

\section{Sreenadha Rao Kanuru}

Anna University Chennai

R. Arul Jothi

Government Arts College

E. Vinoth

Government Arts College

S. Gopinath

Government Arts College

S. Vetrivel

Government Arts College

Original Research

Keywords: Slow evaporation, XRD, UV-Vis-NIR, SEM, Thermal analysis, Z-scan

Posted Date: February 12th, 2021

DOI: https://doi.org/10.21203/rs.3.rs-191511/v1

License: (c) (1) This work is licensed under a Creative Commons Attribution 4.0 International License.

Read Full License

Version of Record: A version of this preprint was published at Journal of Materials Science: Materials in Electronics on April 12th, 2021. See the published version at https://doi.org/10.1007/s10854-021-058256. 


\title{
Piperazine based Zirconium Oxy-Chloride (PzZrOCl) single crystal: A Third Order Nonlinear Optical material for Opto-electronic Device Applications
}

\author{
R. U. Mullai ${ }^{*}$, Sreenadha Rao Kanuru ${ }^{2}$, R. Arul Jothi ${ }^{1}$, E. Vinoth ${ }^{1}$, S. Gopinath ${ }^{1}$, S. Vetrivel ${ }^{1}$ \\ ${ }^{1}$ PG and Research Department of Physics, Government Arts College, Thiruvannamalai 606603, \\ Tamil Nadu, India. \\ ${ }^{2}$ Crystal Growth Centre, Anna University, Chennai-600025, India. \\ Corresponding Author:mullairu@gmail.com.
}

\begin{abstract}
Single crystals of Piperazine Zirconium Oxy-Chloride (PzZrOCl) are grown successfully by slow evaporation technique for Opto-electronic device applications. Suitability of the material is estimated and reported as follows. Crystal habits, purity, crystallite size, microstructure and bulk crystals structures are essential parameters for device compatibility hence they were examined with basic characterization techniques and studied to estimate their effects on optoelectronic properties. The outcomes from structural aspects are reasonably good. The functional groups of a molecule, their bond vibration frequencies and mode of alignments have been examined by Fourier Transform Infrared spectroscopy (FT-IR). The transmittance (98\%) in the entire visible range with lowest cut-off wavelength $(215 \mathrm{~nm})$ and green emission $(545 \mathrm{~nm})$ is another evidence of suitability. The thermal and mechanical strength via hardness, Mayer index, yield strength and elastic stiffness constant is evaluated; it is thermally stable up to $162^{\circ} \mathrm{C}$, mechanically strong and belongs to soft category. Laser induced damage is estimated by using $\mathrm{Nd}$ :YAG laser of wavelength $1064 \mathrm{~nm}$ and the observed values is three times higher than KDP, 1.2 times higher than LAPP. The optical nonlinear nature and its efficiency are examined by using Z-scan technique. The analysis discussed in detailed and the results strongly recommends $\mathrm{PzZrOCl}$ single crystals are suitable for optical and electronic device applications.
\end{abstract}

Keyword: Slow evaporation; XRD; UV-Vis-NIR; SEM; Thermal analysis; Z-scan.

\section{Introduction}

Non-linear optics (NLO) explains the nonlinear response of frequency, phase and path difference of the incident light, polarization density of non-linear media as a function of higher 
orders electric field of the light. Up on the interaction of incident light with non-linear media, generation of light with a doubled, tripled frequency with respect to the incident light termed as Second harmonic generation (SHG), Third harmonic generation (THG). The non-linear processes are non-invasive, non-destructive and highly sensitive towards atomic structure and bonding status, these are promising techniques for interfacial study, light manipulation in nanoscale and in highly sensitive bio-molecular detection [1]. THG and odd-order processes are more convenient as they require less intense beam since the symmetry rules are relaxed in most of the optical materials. It is believed that THG has high conversion efficiency at the crystal-air interface [2] with a normal incidence but the detailed relationship excitation depth, incident angle and THG intensity yet to be mentioned. THG includes the potential applications like production of high power laser sources, high power conversion efficiency, in telecommunication for optical switching and signal processing, in transimition based devices, materials are required with high nonlinear refractive with minimal absorption losses. The other applications include 3D fluorescence imaging; 3D optical data storage [3-9] allows the focused research on the third order nonlinear optical material due to their efficient nonlinear phenomena. In the initial stage for the nonlinear applications inorganic materials are highly explored due to their physical properties, easy to synthesize due to ionic bonding nature. Some of the most useful crystals are like quartz, potassium dihydrogen phosphate (KDP), ammonium dihydrogen phosphate (ADP), barium metaborate, potassium niobium oxide and lithium niobium oxide single crystals etc. These inorganic materials are widely employed in optical devices consequently they have dominated optical technology over the last 40 years. But due to inherent ionic nature and absence of extended $\pi$ electrons makes the available nonlinearities were limited. Later on organic nonlinear optical materials are focused due to their potentially high nonlinear susceptibility $(\chi)$, hyperpolarisability $(\beta)$, modification through standard synthetic methods, and relative ease of device fabrication, high damage resistance and rapid response to electro-optic effect compared to inorganic NLO materials due to delocalized bonds. Many new organic crystals have been examined by their molecular engineering approach and potential applications in telecommunication and optical information process [10]. Instead of screening the known materials for NLO applications, the researchers begin to design new materials with better nonlinearities. But most of the materials are unsuitable for device due to the limitations in mechanical strength, low dimensional properties, poor 3D- bonding and linear optical properties 
of organic materials. Circumstances forced the researchers to search new materials with combined favorable effects of both inorganic and organic materials for the rapid development in photonic technologies. Since photons are capable of processing the information with the speed of the light. The combined effect gives the research on semiorganics which includes the development in the materials with 1) High nonlinear coefficients, 2) High damage threshold, 3) low angular sensitivity, 4) Low UV cut-off; 5) Crystals can be grown in bulk with optimized conditions and 6) Good mechanical properties. It is a new approach for high efficiency where a polarizable organic NLO material is stoichiometrically bonded with an inorganic host material. Semi-Organic materials possesses the combined properties of organic and inorganic which have more appropriate for device fabrication $[11,12]$. In this consequence we chose Piperazine as an organic NLO material since it plays an important role as a unit present in the more complex molecules studied in several field [13-15]. Piperazine in crystals has a chair conformation with $\mathrm{N}-\mathrm{H}$ bonds in the equatorial positions and resides at the crystallographic inversion center [16]. The piperazine ring is used as a building block for pharmaceuticals $[17,18]$ and found to be a biologically active compound due to its privileged structure in drug discovery. It is an achiral organic weak base with excellent hydrogen bond acceptor nature due to this reason it is capable of yielding both second and third NLO properties. Donor-acceptor groups and large $\pi$ delocalization present in the benzene derivatives are responsible for high molecular nonlinearity [19]. It has been found that some polycationic ligand, including Piperidine and Piperazine rings, exhibit a substantial degree of selective RNA building [20].

The other inorganic material is Zirconium oxychloride it is basically a strong acid when reacts with piperazine gives weak coordination bonds. The Zirconium ( $\mathrm{Zr}$ ) based material has high thermal, chemically stable, tunable refractive index [21] corrosion protection, good Young's modulus and high ionic conducting nature. Zirconium finds extensive use as a ceramic material it also has important applications in catalysts [22]. It is also observed that $\mathrm{Zr}$ based crystal complexes enhances the mechanical strength by reducing the plastic deformation [23]. Zirconium based materials are generally possess high transimition percentage, high band gap, high dielectric constant with high refractive index [24]. In the present investigation Piperazinium with Zirconium Oxy-chloride provides a chance to develop NLO materials for their practical applications. The NL phenomenon has been reported with widely used Z-scan technique. The Zscan technique is a popular method to measure the optical nonlinearity of a given material by 
using contrast generating mechanism. It has the advantage of high sensitivity and simplicity is used to measure the third order nonlinear optical properties [25,26].

\section{Experimental procedure}

\subsection{Material synthesis and crystal growth}

In the current work, base compound $\mathrm{PzZrOCl}$ has been synthesized from piperazine (Merch India, 99\%) and zirconium oxychloride (Merch India, 99\%) in equal molar (1:1) ratio. The solvent plays crucial role to grow bulk and transparent single crystals through its way of interaction with faces of crystal and can change the shape of the crystals. Sometimes the solvent effects stoichiometry of the composition and can produce different morphology. Hence in this work we chosen deionized water as a solvent and stoichiometrically weighted piperazine is dissolved in $100 \mathrm{ml}$ solvent and stirred well for $1 \mathrm{~h}$ at room temperature. To the above solution further add small amounts of zirconium oxy-chloride followed by stirring to obtain the homogeneous mixing. The homogeneous mixing allows the degree of bulk mass transfer for growth and influence the crystals shape. Well stirred solution was filtered with filter paper and allows the filtered solution to evaporate at the room temperature. The final solution was covered with polythene sheet and placed in a dark and dust free room for a period of 20 days. We observed colorless crystalline salt and it is recrystallized continuously to get purified salt. The purified salt is well dissolved again in deionized water and by following above procedure for a

period of 15 days to get considerable size single crystals. The good quality crystals are crucial for assessing the best nonlinear properties. The reaction scheme of the title compound is shown in Fig. 1. The PzZrOCl single crystals were grown by slow evaporation solution technique. After the growth period of 35 days, a good quality bulk single crystal of dimension up to $10 \times 10 \times$ $7 \mathrm{~mm}^{3}$ has been harvested. Fig. 2 shows crystal pictures and their crystal habits, it is an external appearance of the crystals. It is observed that crystals of different shapes with various faces may be due to different saturation levels, it is a key factor for the growth kinetics. The well defined and several main habits of $\mathrm{PzZrOCl}$ are solved by WinX-morph software. The interfacial angles are estimated and established first by using a contact goniometer followed by optical goniometry. All the face sets were indexed and found they are all well, equally developed. It is further seen that the growth rates along a, b and c axis are almost equal and acquired crystals are nonhygroscopic, stable at room temperature. The as noticed faces are $(001),(\overline{1} 0 \overline{1}),(\overline{1} \overline{1} 0),(0 \overline{1} \overline{1})$, 


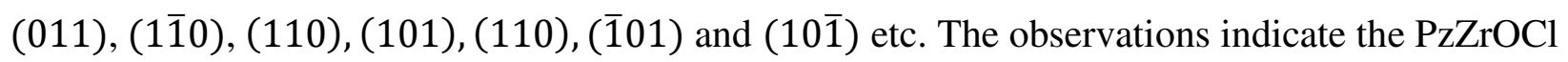
grows as dodecahedron shape.

\subsection{Instrumental specification for characterization}

PzZrOCl single crystals were examined under various characterization techniques to understand the structural, thermal, optical, mechanical and NLO properties. Here we reported the procedure and conditions of characterizations. The crystal structure of as grown PzZrOCl single crystals was evaluated by using PANalytical X'pert Powder XRD system, operated at $30 \mathrm{~mA}$ and $45 \mathrm{kV}$ using $\mathrm{Cu}$-target tube $(\lambda=1.540 \AA$ ) with a curved graphite monochrometer in the $2 \theta$ range $10^{\circ}-70^{\circ}$ at a scan rate of $1 \% \mathrm{~min}$. The lattice parameters and space group of as grown $\mathrm{PzZrOCl}$ single crystals $\left(0.31 \times 0.25 \times 0.20 \mathrm{~mm}^{3}\right)$ were determined by using single crystal XRD system (Bruker Kappa APEXII) with D8 X-ray generator, MoK $\alpha$ radiation $(\lambda=0.710 \AA)$, goniometer (Kappa Cradle) and detector (Apex II CCD Detector) at the room temperature. From the FTIR spectrum the characteristics absorption bands were recorded in the frequency range $400-$ $4000 \mathrm{~cm}^{-1}$ with the help of Shimadzu spectrometer having a resolution of $4 \mathrm{~cm}^{-1}$ by $\mathrm{KBr}$ pallet method. The powdered PzZrOCl sample is diluted with IR inactive $\mathrm{KBr}$ in the 1:100 was used to prepare the pallet. The optical transmission nature of crystal with thickness1.6 $\mathrm{mm}$ is examined at room temperature by using DOUBLE BEAM UV- Vis-NIR Spectrophotometer (Model: 2202) in the region 200-1200nm. The photoluminescence spectral measurement is performed by using Spectra physics tunable laser with Horiba jobin monochrometer and PMT detector. The excitation wavelength is about $244 \mathrm{~nm}$ from Argon ion source. Thermal stability of the crystals was done by thermo gravimetric analysis (TGA) method using Dupont 951 thermo gravimetric analyzers. The test was performed from 30 to $500^{\circ} \mathrm{C}$ at the heating rate of $10^{\circ} \mathrm{C} / \mathrm{min}$ in the nitrogen atmosphere $\left(N_{2}\right)$ with a gas flow rate of $100 \mathrm{ml} \mathrm{min}^{-1}$ with an initial sample of mass $1.72 \mathrm{mg}$. Micro hardness analysis was carried out using Shimadzu model HMV-2T. Ultramicro hardness tester fitted with a Vickers diamond pyramidal intender attached to the MET microscope. The surface morphology and particle sizes of the samples were determined by field emission scanning electron microscopy (FESEM; Hitachi S4800; Japan). $Z$ - Scan is the simple, most popular, accurate, highly sensitive and sophisticated technique in computing the third and higher order nonlinear optical properties based on intensity. It simultaneously allows calculating the nonlinear absorption and nonlinear refractive index to confirm nonlinear nature of 
material. In this technique, the sample under the study of thickness $1 \mathrm{~mm}$ is translated along $Z$ direction of a focused Gaussian beam from the CW Diode pumped Nd: YAG laser at $532 \mathrm{~nm}$ with power $50 \mathrm{~mW}$ and the far field intensity is measured as function of sample position. In the $Z-$ Scan nonlinear refraction and nonlinear absorption is a major material interest by open aperture and closed aperture. Open aperture can estimate the change in transmittance of the medium as a function of intensity i.e. nonlinear absorption coefficient $(\beta)$ by moving the sample through the focus without an aperture at the detector end (open aperture). The closed aperture, one can estimate the amplitude of phase shift (nonlinear refractive index, $n_{2}$ ) by carefully observing the transmittance change through a small aperture at the far field position. The open method is generally used in conjugation with closed method to correct the calculated values. The ratio of the signals from the both methods can be used to determine the nonlinear refraction of the material.

\section{Result and discussion}

\subsection{Powder X-ray diffraction analysis}

It is most widely used rapid and nondestructive technique to identify the unknown crystalline materials through their unique diffraction peaks originating from unique structure. Hence the crystalline structure of $\mathrm{PzZrOCl}$ is examined by taking its finely grounded, homogenized powder on the glass substrate and scanned with step size $0.05^{\circ}$. Various reflections from the respective planes of were identified; their diffraction pattern is depicted in Fig. 2 . The prominent peaks were indexed for tetragonal system using CELREF software. The sharp and intense peaks confirm well-ordered atomic planes and the crystallites are pure and dislocation free within the sensitivity of the measurement. The intensity of the peaks is due to size and orientation of the crystallites. The purity is further confirmed by fitting the highest intensity peaks with theoretical Gaussian model. The full width at half maxima (FWHM) for the highest intensity peak corresponding to (321) plane centered at $27.88^{\circ}$ is $0.465 \operatorname{arcsec}$ with peak height 0.967. Similarly the FWHM for the planes (401), (441) with peak heights $0.584,0.344$ centered at $31.17^{\circ}$ and $42.30^{\circ}$ is $0.420,0.377$ arcsec respectively. The insight figure represents the deconvolution of highest intensity peak. It is clear that the curve has no additional peaks which supports the crystalline perfection is reasonably good. Moreover, for the above mentioned planes the crystallite size $(P)$ was calculated by using the formula. 


$$
P=k \lambda / \beta \cos \theta
$$

Where, $k$ is Scherrer constant (0.9), $\lambda$ is $\mathrm{X}$-ray wavelength, $\beta$ is the broadening at half maximum intensity (FWHM) and $\theta$ is Bragg's angle. Since crystallite phase and particle size is effective parameters in determining the Band gap. The observed crystallite size for the planes (321) and (401) is 0.30 and $0.34 \mathrm{~nm}$ respectively.

\subsection{Single crystal $X$-ray diffraction (XRD) analysis}

Visibly transparent, defect free (cracks and inclusions) and well shaped single crystal of $\mathrm{PzZrOCl}$ were selected for single crystals $\mathrm{X}$ - ray diffraction studies at the room temperature. The obtained lattice parameter values are $a=6.46 \AA, b=12.81 \AA, c=12.85 \AA$, $\alpha=$ $89.95^{\circ}, \beta=89.96^{\circ}$ and $\gamma=90.03^{\circ}$ and the volume of the unit cell found to be $\mathrm{V}=1063 \AA^{3}$. The single crystal XRD studies reveal that the PzZrOCl crystal belongs to the tetragonal system with space group P. The unit cell volume is increased 4.3 times to that of Piperazine monoclinic, $P 2_{1} / n\left(V=249.05 A^{\circ 3}\right)$ [27]. The increase in cell volume may be due to the development of internal strain caused by the monoclinic, $\left(P 2_{1} / n\right)$ distortion in to tetragonal $(P)$. It confirms the reaction between zirconium oxychloride with piperazine. The change in crystal system confirms the zirconium oxy chloride doped in host lattice.

\subsection{FT-IR analysis}

The advantage of FT-IR spectroscopy is the structural identification of functional groups. In this analysis all the functional groups of molecule absorbs the energy in definite frequency range and causes bond vibrations in stretch or bend with respect to neighboring molecules. The observed vibrational frequencies were confirmed quantitatively and their assignments are recorded in FTIR spectrum which is shown in Fig.3. The heteroaromatics N-H group shows its $\mathrm{N}-\mathrm{H}$ stretching absorption at $3240 \mathrm{~cm}^{-1}$ [28]. The symmetric and asymmetric stretching of $\mathrm{C}-\mathrm{H}$ is observed at $2821 \mathrm{~cm}^{-1}$ and $2757 \mathrm{~cm}^{-1}$. The presence of peak at $2620 \mathrm{~cm}^{-1}$ confirms N-H--O vibration of the amine with zirconium oxy chloride. The presence of water is confirmed by a shoulder peak at $1666 \mathrm{~cm}^{-1}$. The peak at $1558 \mathrm{~cm}^{-1}$ is assigned to aromatic ring vibrations. The aliphatic $\mathrm{CH}_{2}$ groups are present at 1441 and $1381 \mathrm{~cm}^{-1}$ respectively. The peak appeared at 1381 $\mathrm{cm}^{-1}$ is due to $\mathrm{CH}_{2}$ bending mode. The evident of $\mathrm{Zr}-\mathrm{O}$ stretches are illustrated at $1319 \mathrm{~cm}^{-1}$ [29]. The peaks at 1198 and 1063 are due to asymmetric and symmetric stretching vibrations of C-N 
group. FTIR absorption peak at about $888 \mathrm{~cm}^{-1}$ region is due to $\mathrm{Zr}-\mathrm{O}$ vibration [30, 31]. The peak at $761 \mathrm{~cm}^{-1}$ is due to $\mathrm{N}-\mathrm{H}$ bending mode. The CCN deformation is assigned at $579 \mathrm{~cm}^{-1}$. All these observations represent the presence of zirconium oxy-chloride in the piperazine crystal lattice.

\section{$3.4 \quad U V$-vis- NIR spectral analysis}

The optical absorption and transmittance spectrum of the grown crystal was recorded and the resultant spectrum is shown in Fig.4. Generally, the spectrum in UV visible is due to the transition from one electronic sate to other electronic state hence the absorption depends on the electronic structure of the molecule. From the spectrum, the transimition is quite low below the band gap region; it may be due to presence of defects or free charge carriers. Further, the transmittance suddenly decreases in the short wavelength region due to the band gap absorption. Moreover, from absorption spectrum it is clear that the absorption is decreasing with increasing wavelength and becomes very small in visible to IR region $(\lambda>300 \mathrm{~nm})$ hence the crystal is transparent in the entire visible to IR region. The UV cut off wavelength is found to be $215 \mathrm{~nm}$ below which the material itself absorbs all the light. The UV cut off is due to electronic transition from top of the valence band to bottom of the conduction band i.e. $n \rightarrow \pi^{*}$ or ligand to metal. Cut off wavelength is an essential parameter for deciding the candidature of a material. The observed cutoff wavelength is shorter than the reported cutoff wavelength $260 \mathrm{~nm}$ of piperazine. Such a lower cut off is due to lack of delocalized charge distributions. Generally, the drop in the cutoff wavelength is due to incorporation of some unknown impurities [32], but in present case indicates the incorporation of zirconium oxy-chloride in piperazine lattice. In present case the estimated band gap $5.76 \mathrm{eV}$ indicates the grown crystals have very low defect concentration and high transmittance in visible region. Such wide band gap allows the crystal with high optical conductivity with absorption of photons in a particular range of frequency. The very low absorption in the entire visible region confirms its suitability for making the nonlinear optical devices in generating blue-green light using a diode laser. The wide band gap infers PzZrOCl is highly NLO active and possess high optical and low electrical conductivity. Hence the PzZrOCl single crystals are dielectric nature, optically transparent in the UV-Vis region with 98\% transmission level. There is no considerable absorption of light to any appreciable extent in the entire visible region of electromagnetic spectrum, which is the intrinsic property of all amino 
acids such as absence of strong conjugated bonds and also filled $d^{10}$ shells of the metal ion in the complex [33]. These results infer $\mathrm{PzZrOCl}$ is suitable candidate for frequency doubling.

\subsection{Photoluminescence analysis}

Photoluminescence (PL) is a type of electromagnetic spectroscopy that investigates fluorescence from a given material. The structural perfection, crystalline quality and luminescence property of the grown crystal are identified using the fluorescence study. It has wide application in the branches of medical, chemical and biochemical research fields. PL studies are most preferable compare to optical absorption to detect the lower concentration of defects. The emission spectrum was recorded and shown in Fig. 5. The sample was excited at $244 \mathrm{~nm}$ and the emission peak was observed at $545 \mathrm{~nm}(2.27 \mathrm{eV})$, which is Green emission corresponds to the $\mathrm{n}-\pi^{*}$ transition. The strong emission in the observed band gap region may be due to the presence of intrinsic defects in the forbidden band gap region. From this the grown $\mathrm{PzZrOCl}$ is suitable for optoelectronic applications.

\subsection{Morphological studies}

The analysis on the microstructure of grown single crystals is an essential parameter for device applications because only few facets are usable. Some crystals during the growth do exhibit microstructures on their habit faces. The surface morphology of such a grown crystal has been shown in Fig.6. It indicates layered like growth of the crystals, further the grown layers spreading from the nucleus. The observed microstructures suggesting the crystal growth by twodimensional spreading and filing up of layers indicates growth at high supersaturation and moreover the surface brighter and darker uneven areas which is most commonly observed in solution grown crystals.

\subsection{Thermal analysis}

The thermal stability of $\mathrm{PzZrOCl}$ crystal was carried out, the respective Thermogravimetry (TG), Differential thermal analysis (DTA) is shown in Fig.7. Under the TG technique, one can determine the change in the weight of the sample during either heating or cooling of the sample. From the TG curve it is inferred that the title compound undergo decomposition in three stages with total weight loss $92.33 \%$ material into gaseous products. The decomposition with minute weight loss starts around $129^{\circ} \mathrm{C}$ and ends at $292^{\circ} \mathrm{C}$. The minute 
weight loss may be attributed due to loss of water molecules; the compound cannot undergo any significant phase transition but decomposes without melting. Hence the material is thermally stable up to $129^{\circ} \mathrm{C}$ in crystalline solid form, beyond it compound becomes soften and starts melt. FTIR spectrum also confirms the presence of water molecules with a peak at $1666 \mathrm{~cm}^{-1}$. The major weight loss starts from $169^{\circ} \mathrm{C}$ to $292^{\circ} \mathrm{C}$. It may be due to evolution of various gaseous products such as $\mathrm{CO}_{2}, \mathrm{OH}, \mathrm{NO}_{2}, \mathrm{NH}_{3}$ and hydrocarbons. The residual mass of $0.132 \mathrm{mg}(7.66 \%)$ out of $1.724 \mathrm{mg}(100 \%)$ which is left in the crucible may be carbon mass present after all the decomposition processes completed. From this study, the sharp weight loss $\left(6.99 \% /{ }^{\circ} \mathrm{C}\right) 169^{\circ} \mathrm{C}$ is assigned as the melting point of the crystal hence this compound can be used for device fabrication below this melting point. The DTA is a popular technique to measure how a physical quantity of a sample changes with temperature. The DTA curve shows that four exothermic peak at around $129^{\circ} \mathrm{C}, 162^{\circ} \mathrm{C}, 247^{\circ} \mathrm{C}$ and $292^{\circ} \mathrm{C}$ respectively. A small hump around $129^{\circ} \mathrm{C}$ with FWHM 21.43 is basically not responsible for any phase transition but may be due to the release of water molecules used as a solvent during the crystal growth. A second sharp endothermic peak at $162^{\circ} \mathrm{C}$ with FWHM 6.23 is assigned to the melting point of the title compound. The third endothermic peak at $248^{\circ} \mathrm{C}$ with FWHM 7.14 could be indication of other gases elimination. The fourth endothermic peak at $292^{\circ} \mathrm{C}$ may be due to the removal of the hydroxyl and amino groups expelled from the compound respectively $[34,35]$. The peak sharpness of the peaks indicates the purity of the material.

\subsection{Mechanical measurements}

Mechanical strength is direct consequence of structure (molecular bonding) and composition of the material and it was demonstrated by using hardness measurement. It is a nondestructive technique, plays a vital role in device fabrication [36]. Under this investigation by studying the resistance offered by the crystal lattice to the local deformation, one can analyze the mechanical properties; such as fracture behavior, yield strength, brittleness index and temperature of cracking. According to Gong [37], in the process of indentation, the external work done on the crystal surface by the intender gets converted to component strain energy which is proportional to volume of the resultant impression. Hence surface energy component is also proportional to the area of the impression. The diagonal length $(d)$ in $\mu m$ for different loads $P$ between 25 to $100 \mathrm{~g}$ measured for same indentation period of $10 \mathrm{~s}$ for all the trails. The 
parameters like diagonal length, indentation marks and crack length were calculated, using the micrometer eyepiece. The Vicker's microhardness number $\left(H_{v}\right)$ was calculated using the relation [38].

$$
H_{v}=\frac{1.8544 P}{\left(d^{2}\right)} \mathrm{kg} / \mathrm{mm}^{2}
$$

Where $P$ is the load applied and $d$ is the length of diagonal in the Vicker's indenter impression, $H_{v}$ is the hardness number. The variation of $H_{v}$ with applied load for the as grown $\mathrm{PzZrOCl}$ is shown in the fig. 8. From the graph it is absorbed that, the hardness number increases with increasing load, which exhibits reverse indentation size effect (RISE). The micro hardness value was taken as the average of the several impressions made. Further loading results in development and propagation of the clack across the specimen around the indentation mark with dimensions Left: 18.16 Right: 29.14 UP: 16.14 Down: $21.61 \mu m$ respectively. At the smaller loads the penetration depth of the indenter is only on the surface level and the generated stress is considered to be minimum. On increasing the load, the penetration depth increases up to inner layers. The stress generated at walls ultimately causes the crack and the plastic deformation. Observed moderately high hardness number $49.35 \mathrm{~kg} / \mathrm{mm}^{2}$ at $100 \mathrm{~g}$ can be attributed to strong intermolecular hydrogen bond interactions and the ionic character of the compound. Strong bonding nature is an additional advantage that it can be utilized in fabrication of electro-optic devices. The plot between $\log \mathrm{d}$ and $\log \mathrm{P}$ is given by Meyer's law and it is observed straight line behavior.

$$
P=k_{1} d^{n}
$$

Where $k_{1}$ the material's constant and $n$ is Meyer's index or work hardening coefficient. The plot $\log P$ versus $\log d$ for $\mathrm{PzZrOCl}$ is shown in the fig. 9. In the present study the graph yields a straight line and slope gives the work hardening index $(n)$ is estimated to be 3.31 by linear fitting. According Kick's law, for normal Indentation Size effect (ISE), hardness decreases with increasing the load on the crystal and $n<2$, for RISE behavior $n>2$, where the hardness increases with increasing load. It is true in our system and $\mathrm{PzZrOCl}$ comes under soft category [39].

\subsection{Laser damage threshold studies}


An NLO material to be a good candidate for laser applications, the main and essential criteria is its Laser damage threshold (LDT). It is the maximum limit of fluency (energy/area) beyond which an optical material will be damaged permanently. The several intrinsic and extrinsic factors may affect the induced bulk damage. Generally, the intrinsic factors includes linear absorption, self-focusing, stimulated Brillouin and Raman scattering, electron avalanche breakdown. The extrinsic defects like voids, impurities and finishing of the surface. The LDT initiates some modification in the material under examination. The defects and destroyed sites along path of the beam can cause a drop in energy of transmitted beam through the target. It depends on the material properties and laser beam properties like pulse width, laser wavelength, beam spot on the sample and laser mode (transverse/longitudinal). High tolerance of surface damage is an important factor for NLO and optoelectronic applications. Hence in the present investigation the LDT value for PzZrOCl is evaluated by using Q- switch Nd: YAG laser with wavelength ( $\lambda$ ) $1064 \mathrm{~nm}$ operated in transverse mode $\left(\mathrm{TM}_{00}\right)$. The other parameters used in irradiating the sample and calculating LDT were pulse width $(\tau) 6 \mathrm{~ns}$, frequency rate $(v) 10 \mathrm{~Hz}$, laser beam diameter (d) $1 \mathrm{~mm}$. The intensity of the output laser beam is controlled by a variable attenuator and brought to focus on the crystal with a converging lens of focal length $(f) 10 \mathrm{~cm}$. This lens helps us to set the beam spot on the sample to a desired value (beam diameter $d^{\prime}$ ). During the process of irradiation, the damage on the surface can be estimated by visual formation of the damage and input energy density of laser beam where the crystal gets damaged is recorded by power meter. The damage of the crystals caused by the power density $\left(P_{d}\right)$ is calculated by the following relations.

$$
\text { Power density }\left(P_{d}\right)=E_{p} / \tau \pi r^{2} \mathrm{~W} / \mathrm{cm}^{2}
$$

Where $E_{p}$ is input pulse energy in milli joule (38.7) of the laser beam where the damage has occurred, $\tau$ the pulse width, $t$ is thickness of the sample and $r$ is the radius of the circular beam spot on the sample $\left(d^{\prime} / 2\right)$, it can be calculated as follows.

$$
d^{\prime}=1.27 \lambda f / t
$$

The value of $d^{\prime}$ is obtained as $0.057 \mathrm{~mm}$. The calculated laser damage threshold value for $\mathrm{PzZrOCl}$ is $0.6 \mathrm{GW} / \mathrm{cm}^{2}$. The observed value is three times higher than $\mathrm{KDP}\left(0.2 \mathrm{GW} / \mathrm{cm}^{2}\right)$ [40] and 1.2 times higher than LAPP $\left(0.50 \mathrm{GW} / \mathrm{cm}^{2}\right)$ [41]. Thus PzZrOCl has good optical damage 
tolerance, it is suitable high power laser applications. Aside from thermal effects, multiphoton absorption the mechanical hardness of the material also affects the laser induced damage.

\subsection{Non-linear properties: Z-scan technique}

The third order non-linear optical properties can be evaluated from a standard Z- scan technique. It is an appropriate technique to determine the nonlinear refractive index $\left(n_{2}\right)$, effective nonlinear absorption $(\beta)$ and optical susceptibility $\left(\chi^{(3)}\right)$ etc, of the medium with high accuracy. This can be done by analyzing the distortions in spatial, spectral and temporal parameters of the high power laser radiation. In order to represent experimental data of the nonlinear indices and nonlinear absorption coefficient widely used Gaussian decomposition method was adopted and its description was given in $[42,43]$. The nonlinear refraction can be estimated from the closed aperture (i.e. aperture is placed in the far field). In the closed aperture the sample is allowed to move along the propagation direction $\mathrm{Z}$ with respect to the focal plane by keeping the power fixed. The normalized transmittance of the sample through the aperture is estimated in the far field as a function of sample position. The intensity dependent refractive index changes the radius of the transmitted beam while the Gaussian profile remains same. The closed aperture scan for grown crystal is shown in fig. 10. The symbols in figure represent experimental data, while the solid lines are by fitting the experimental data with theoretical modes. From the closed aperture measurement nonlinear refractive properties like selffocusing $\left(n_{2}>0\right) /$ self-defocusing $\left(n_{2}<0\right)$ can be analyzed. Moreover, the sign of the nonlinear refraction is readily obtained from a Z-scan signature. A peak-valley configuration denotes a negative nonlinearity and a valley-peak denotes a positive nonlinearity. A pre-focal transmittance maximum (peak) followed by post focal transmittance a minimum (valley) corresponds to negative non-linearity [44] i.e. $n_{2}$ is negative. It implies Kerr-focal length is negative from the equation $F=b \omega_{0}^{2} / 4 \operatorname{LIn}_{2}$ (where $b$ is correction term, $L$ is the thickness of the sample (non-linear medium), $I$ is the irradiance and $\omega_{o}$ is Gaussian beam radius (beam waist)) which leads to the self-defocusing of the incident beam. The result from fig. 10 indicates the as grown PzZrOCl single crystals can also be used as self-defocusing material (concave lens) around $532 \mathrm{~nm}$. It is due to spatial distribution of temperature which produces localized absorption of the tightly focused laser beam in the material which in turn local variation in refractive index of $\mathrm{PzZrOCl}$. Hence the material act as a thermal lens, it defocus the incident 
laser beam. The defocusing nature of this material is an essential property which can apply in protecting the optical sensors such as night vision devices [45]. Moreover, the reliability in measuring the nonlinear refractive index can also be confirmed by taking the difference between peak and valley transmission i.e. $\Delta T_{p-v}$ and $\Delta Z_{p-v} \sim 1.7 z_{0} . z_{0}=\pi \omega_{0}^{2} / \lambda$ is the Rayleigh range. Hence the nonlinear refractive index $\left(n_{2}\right)$ is given by

$$
n_{2}=\Delta \varphi_{0} / k I_{0} L_{e f f}
$$

Where $k=2 \pi / \lambda$ is the wavenumber, $I_{0}$ is the intensity of the laser beam at $Z=0$ and $L_{e f f}=\left[1-e^{(-\alpha L / \alpha)}\right]$ is the effective thickness of the sample, $\alpha$ is linear absorption and $L$ is the thickness of the sample.

The open aperture (a lens replaced by aperture) scans for grown crystals are shown in fig. 11. From the open aperture scans one can analyze the non-linear absorption. It might be due to saturable absorption (SA) / reverse saturable absorption (RSA) by estimating effective nonlinear absorption $(\beta)$. The value of $\beta$ will be negative for saturable absorption and positive for reverse saturable absorption. In SA, absorption coefficient decreases with increase in transmittance where as in RSA, absorption coefficient increases with decrease in transmittance. In SA the absorptive properties fade with increasing the intensity of the laser beam due to depletion of the ground state. In RSA, the absorption in the excited sate is large compared to ground state hence the absorption undergo reverse process. It can result in large absorption by the non-linear medium; it can happen multi-photon absorption (MPA) in which simultaneously two or more photons was absorbed either from ground sate of same energy level or from excited state. It reflects in reduction in peak and enhances valley. From the open aperture, in the $\mathrm{PzZrOCl}$ it can be seen that the transmittance minimum lies near the focus $(Z=0)$ and peak is suppressed and enhances the valley at $Z=0$. It indicates $\mathrm{PzZrOCl}$ possess nonlinear absorption nature. Similarly the saturation absorption reduces the valley and enhances the peak $[42,46]$. The two photon absorption has great impact in performance of switching devices for optical computing and telecommunication applications. The above results help us to use $\mathrm{PzZrOCl}$ as good $\mathrm{RS}$ absorber in visible region. The two photon absorption must be minimized relative to nonlinear refractive change for optical switches. From open aperture $\beta$ can be calculated as follows.

$$
\beta=2 \sqrt{2} \Delta T / I_{0} L_{e f f}
$$


Where $\Delta T$ is the peak value on the open aperture $Z$ - scan curve. The calculated value for $\beta$ is $5.40 \times 10^{-6}(\mathrm{~cm} / W)$ and it is lesser than 0 , a positive value. Hence the non-linear absorption is due RSA in particular two photon absorption (TPA). The positive nonlinear absorption may be due to electron excitation via interband transition. $\beta<0$ is due to positive value of $\operatorname{Im} \chi^{(3)}$. Such a low value of $\beta$ compared to the materials in literature $[47,48]$ is due to the poor delocalization of the donar and acceptor group of piperazine and zirconium oxy-chloride molecules. The figure of merit (FOM) $\mathrm{B}$ of $\mathrm{PzZrOCl}$ for all optical switching applications is estimated as follows. $B=\left(\lambda \beta / n_{2}\right)$ where $n_{2}$ is nonlinear refractive index, $\beta$ is two photon absorption coefficient and $\lambda$ wavelength of laser light used. The FOM value for $\mathrm{PzZrOCl}$ is $7.32 \times 10^{-3}$. The two photon figure of merit $T=\left(n_{2} / \lambda \beta\right)$ is simply the inverse of figure of merit and it is observed for $\mathrm{PzZrOCl}$ as $1.37 \times 10^{2}$.

The real and imaginary parts of the third order nonlinear optical susceptibility $\chi^{(3)}$ were estimated from experimental determination of $n_{2}$ and $\beta$ according to the following relations.

$$
\begin{aligned}
& \operatorname{Re} \chi^{(3)}(\mathrm{esu})=10^{-4} \varepsilon_{0} C^{2} n_{0}^{2} n_{2} / \pi\left(\mathrm{cm}^{2} / W\right) \\
& \operatorname{Im} \chi^{(3)}(\mathrm{esu})=10^{-2} \varepsilon_{0} C^{2} n_{0}^{2} n_{2} \lambda \beta / 4 \pi^{2}(\mathrm{~cm} / W)
\end{aligned}
$$

Where $\varepsilon_{0}$ is the free space permitivity, $n_{0}$ is the linear refractive index of the sample and $C$ is the velocity of light in vacuum. The absolute value of $\chi^{(3)}$ was calculated from the following relation.

$$
\left|\chi^{(3)}\right|=\left[\left(\operatorname{Re} \chi^{(3)}\right)^{2}+\right.
$$

$$
\left.\left(\operatorname{Im} \chi^{(3)}\right)^{2}\right]^{1 / 2}
$$

In the above equation the real and imaginary parts of $\chi^{(3)}$ are direct consequence of hyperpolarizability of the given system. These parameters are not directly obtained by experimental methods hence open and closed aperture processes since $n_{2} \propto \operatorname{Re} \chi^{(3)}, \beta \propto$ $\operatorname{Im} \chi^{(3)}$. The real part $\operatorname{Re} \chi^{(3)}$ accounts for transient effects (like optical Kerr effect, molecular orientation, electrostriction etc.) consumes no energy while imaginary part $\operatorname{Im} \chi^{(3)}$ accounts for the process that involves in two photon absorption. From calculated values of $\operatorname{Re} \chi^{(3)}$ and $\operatorname{Im} \chi^{(3)}$, it is observed that $\operatorname{Re} \chi^{(3)}>\operatorname{Im} \chi^{(3)}$. It is an intrinsic property of NLO material. Thus absolute $\chi^{(3)}$ acts like a figure of merit to investigate the potential material for photonic 
applications. The third order nonlinear optical susceptibility $\left(\chi^{3}\right)$ of $\mathrm{PzZrOCl}$ single crystals is $10.39 \times 10^{-9} \mathrm{esu}$. The observed values for $n_{2}$ and $\beta$ indicates the potential capability of this material which can efficiently produce non linear (NL) effects. $\beta$ and $\chi^{3}$ are compared with some of the existing literature based on Piperazine and other compounds further confirm the material is promising candidate for optical limiting applications. Generally, we know the transmittance versus sample position in closed and open aperture gives $n_{2}$ and $\beta$. But the closed aperture transmittance is affected by both $n_{2}$ and $\beta$. Hence the determination of $n_{2}$ from closed aperture transmittance is not more accurate. Therefore it is mandatory to separate the effect of $n_{2}$ from that of $\beta$. A simple is applied to obtain purely effective $n_{2}$ from that of closed aperture is just by dividing its transmittance with corresponding open aperture transmittance. Fig. 12 indicates such a plot which reflects purely the effect of $n_{2}$. From this characterization the all observed values are summarized in the table 1 .

\section{Conclusion}

Single crystals of PzZrOCl were synthesized and crystallized using piperazine and zirconium oxy chloride as a starting material by slow evaporation method at room temperature. Crystals are transparent colorless with $10 \times 10 \times 7 \mathrm{~mm}^{3}$ dimensions. Crystalline phase, purity and cell parameters were confirmed with powder X-ray diffraction and single crystals X-ray diffraction techniques. The crystalline quality is reasonably good and crystal belongs to tetragonal system with space group P. Structural identification of functional groups is examined by FT-IR spectroscopy. The suitability of the crystals for the optical application was tested by UV-VisNIR and fluorescence spectroscopy. The lower cutoff wavelength and high transparency in the entire visible region and green emission from $\mathrm{PL}$ proves $\mathrm{PzZrOCl}$ is a potential candidate for optical device applications. FESEM analysis on the grown single crystals reveals layered like growth under 2D growth mechanism. Further thermal stability analyzed by TG/DTA technique confirms the title compound thermally stable up to $169^{\circ} \mathrm{C}$. Mechanical strength of the PzZrOCl is tested with microhardness measurement. The crystal exhibits reverse indentation size effect and there was not a significant crack till $100 \mathrm{~g}$ load. The work hardening index $(n)$ is estimated to be 3.31 by linear fitting and PzZrOCl comes under soft category. Laser induced damage threshold value is $0.6 \mathrm{GW} / \mathrm{cm}^{2}$. The observed value is three times higher than $\mathrm{KDP}(0.2$ $\left.\mathrm{GW} / \mathrm{cm}^{2}\right)$ and 1.2 times higher than LAPP $\left(0.50 \mathrm{GW} / \mathrm{cm}^{2}\right)$. The Z- scan technique on the present 
material with relative third order nonlinear refractive index $\left(n_{2}\right)$, effective nonlinear absorption $(\beta)$ and optical susceptibility $\left(\chi^{(3)}\right)$ indicates it can also capable of generating third harmonics. It is concluded that $\mathrm{PzZrOCl}$ is a suitable candidate for optoelectronic applications.

\section{Acknowledgements}

The authors are thankful to Dr. Vinitha. G, Asst. Professor, School of Advanced Sciences, Physics, VIT Chennai-600127, India for extending their Z-scan technique facility and her fruitful suggestions.

\section{Reference}

[1] Gao Yi, Hyub Lee, Jiao Jiannan, Byung Jae Chun, Seunghwoi Han, Hyunwoong Kim, Yong Wookim, Donghwan Kim, Seung-woo Kim and Young- Jin Kim, Nonlinear third harmonic generation at crystalline sapphires, Opt. Express, 25 (2017) 26002.

[2] P.N.Sacta and N.A.Miller, Distinguishing surface and bulk contributions to third-harmonic generation in silicon, Appl. Phys. Lett. 79 (2001) 2704-2706.

[3] J.M. Hales, S.J.Zheng, S.Barlow, S.R.Marder, J.W.Perry, Bisdioxaborine polymethines with large third-order nonlinearities for all-optical signal processing, J.Am. Chem. Soc. 128 (2006) 11362-11363.

[4] S.R.Marder, B.Kippelen, A.K.Y.Jen, N.Peyghambarian, Design and synthesis of Chromophores and Polymers for electro-optic and photorefractive applications,Nature 388 (1997) 845-851.

[5] W.Denk, J.H. Strickler, W.W.Webb,Two-photon laser scanning fluorescence microscopy, Science 248 (1990) 73-76.

[6] C.C.Corredor, Z.L.Huang, K.D.Belfield, A.R.Morales, M.V.Bondar, Photochromic polymer composites for two-photon 3d optical data storage, Chem. Mater. 19 (2007) 5165-5173.

[7] B.H. Cumpston, S.P.Ananthavel, S.Barlow, D.L. Dyer, E.Jeffrey, Two-photon polymerization initiators for three-dimensional optical data storage and microfabrication, Nature 398 (1999) 51-54. 
[8] R.Zieba, C.Desroches, F.Chaput, M.Carlsson, B.Eliasson, C.Lopes, M.Lindgren, S.Parola, Preparation of functional hybrid glass material from Platinum (II) complexes for broadband nonlinear absorption of light, Adv. Funct. Mater. 19 (2009) 235-241.

[9] P.Rekha, G.Peramaiyan, M.Nizan Mohideen,R.Mohan Kumar, R.Kanagadurai, Synthesis, growth and characterization of a new organic three dimensional framework: Piperazin-1-ium 4aminoben zenesulfonate, J. Cryst. Growth, 441 (2016) 18-25.

[10] T.Mallik, T.kar, Crystallization and characterization of nonlinear optical material L-arginine formomaleate ,Mater. Lett. 61 (2007) 3826-3828.

[11] K.Boopathi, P. Ramasamy, G.Bhagavannarayana., Growth and characterization of Cu (II) doped negatively soluble lithium sulfate monohydrate crystals, J. Cryst. Growth, 386 (2014) 3237.

[12] K.Boopathi, P.Rajesh, P. Ramasamy, Growth of negative solubility lithium sulfate monohydrate crystal by slow evaporation and Sankaranarayanan- Ramasamy method, J. Cryst. Growth, 345 (2012) 1-6.

[13] T. Eicher, S.Hauptmann, The chemistry of Hetrocycles, G.Thieme Verlag, Stuttgard, 1995. [14] P.H.Stahl, C.G.Wermuth (Eds.), Handbook of Pharmaceutical salts properties, selection and use, Wiley- Vch, Weinheim, 2002.

[15] J.D.Abraham (Ed.), Burger's Medical chemistry and Drug Discovery, Wiley-Interscience, Hoboken, NY, 2003.

[16] S.Ranga Reddy, P.Manikyamba, Solvent effects in the reaction between piperazine and benzyl bromide, J. Chem. Sci. 119 (2007) 613-616.

[17] R.D.Topsom, The nature and analysis of substituent electronic effects, Prog. Phys. Org. Chem. 12 (1976) 1.

[18] M.K.Kaloustain, N.Dennis, S.Mager, S.A.Evans, F.Alcudia, E.L.Eliel, Conformational analysis. XXXI. Conformational equilibria of 1, 3-dioxanes with polar substituents at C-5, J.Am. Chem. Soc. 98 (1976) 956-965. 
[19] R.Geetha Kumari, V. Ramakrishanan, M.Lydia Caroline, J.Kumar, Andrei Sarua, Martin Kuball, Raman spectral investigation of thiourea complexes, Spectrochem. Acta A 73 (2009) 263-267.

[20] Z.Dega-Szafran, M.Jaslolski, I.Kurzyca, P.Barczynski, M.Szafran, Molecular structure, hydrogen bonding, basicity and spectroscopic properties of N,N'-dimethylpiperazine betaines and their hydrohalides, J. Mol. Struct. 614 (2002) 23-32.

[21] T.F Liu,D Feng, YP Chen, L Zou, M Bosch, S Yuan, Z Wei, S Fordham, K Wang, HC Zhou, Topology-guided design and syntheses of highly stable mesoporous porphyrinic zirconium metal-organic frameworks with high surface area, J. Am. Chem. Soc., 2015, 137: 413-419.

[22] M.Stoia, P.Barvinschi, L.Barbu- Tudoran, A.Negrea, and F.Barvinschi, "Influence of thermal treatment on the formation of Zirconia nanostructured powder by thermal decomposition of different precursors", Journal of Crystal Growtth, vol.381, pp 93-99,2013.

[23] Georgiy Fristove, Yuri Koval, Andrei Timoshevskii, Sergey Yablonovskii, Jan Van Humbeeck, Chemical bonding and crystal structure of $\mathrm{Zr}$ - based intermetallic high-temperature shape memory alloys, Chemistry of metals and alloys 6 (2013) 205-208

[24] Seyedeh Leila Panahi, DavoudDastan and N.B.Chaure, Synthesis and Characterization of Zirconium dioxide Nanoparticles grown by sol-gel technique, Advanced Science Letters, 22 (2016) 941-944.

[25] C.Gayathri, A.Ramalingam, Z-Scan determination of the third- order optical nonlinearities of an azo dye using diode-pumped Nd-YAG laser, Optik 119 (2008) 409-414.

[26] T.D.Krauss, F.W.Wise, Femto second measurement of nonlinear absorption and refraction in Cds, Znse, and Zns, Appl. Phys. Lett.65 (1994) 1739-1741.

[27] Andrew Parkin, lain DH Oswald and Simon Parsons, Structures of piperazine, Piperidine and morpholine, Acta. Cryst. B. 60 (2004) 219-227.

[28] S.Gunasekaran, B.Anitha, Spectral investigation and normal coordinate analysis of piperazine, Indian J. pure and Appl. Phys., 46 (2008) 833-838. 
[29] S.Kumar, S.Bhunia, A.K.Ojha, Effect of calcination temperature on phase transformation, structural and optical properties of sol-gel derived ZrO2 nanostructures, Physica E.66(2015)7480.

[30] O.A.Kholdeeva, G.M.Maksimov, R.I.Maksimovskaya, M.P.Vanina, T.A.Trubitsina, D.Yu.Naumov, B.A.Kolesov, N.S.Antonova, J.J.Carbo, J.M.Poblet, $\mathrm{Zr}^{\mathrm{IV}}$ - Monosubstituted keggin- type dimeric polyoxometalates: Synthesis, characterization, catalysis of $\mathrm{H}_{2} \mathrm{O}_{2}$ - based oxidations, and theoretical study, Inorg. Chem., 45 (2006) 7224-7234.

[31] R.Villanneau, H.Carabineiro, X.Carrier, R. Thouvenot, P.Herson, F.Lemos, F.Ramoa Ribeiro, M.Che, Synthesis and characterization of $\mathrm{Zr}$ (IV) polyoxotungstates as molecular analogues of zirconia- supported tungsten catalysts, J. Phys. Chem. B, 108 ( 2004) 12465-12471. [32] Liu, X.Chen, L.X.Huang, X.Xu, G.Zhang, N.Ye, Growth and optical properties of UV transparent YAB crystals, material research innovation 15 (2011) 140.

[33] M.Narayan Bhat, S.M. Dharmaprakash, New nonlinear optical material: glycine sodium nitrate, J. Cryst. Growth 235 (2002) 511-516.

[34] K.A. Nandekar, J.R.. Dontulwar, W.B. Gurnule, Thermoanalytical studies and kinetics of newly synthesized copolymer derived from P-hydroxybenzoic acid, and semicarbazide, Rasayan J. Chem, 5 (2012) 261-268.

[35] R.A. Khatri, S.S.C. Chuang, Y.Soong, M.Gray, Thermal and chemical stability of regenerable solid amine sorbent for $\mathrm{CO}_{2}$ capture, Energy Fuels 20 (4) 2006, 1514-1520.

[36] K. Sangwal, Etching of crystals; Theory, experiments and application, North Holland physics publishing, Amsterdam, Oxford, New York, Tokyo, 1987.

[37] J. Gong, Y. Li, An energy-balance analysis for the size effect in low-load hardness testing, J. Mater. Sci. 35 (2000) 209-213.

[38] M.Magesh, G.Bhagavan narayana, P.Ramasamy, Synthesis, crystal growth and characterization of an organic material: 2-Aminopyridinium Succinate succinic acid single crystal, Spectrochimica Acta part A: Molecular and Biomolecular spectroscopy 150 (2015) 765771 
[39] R.Ezhil Vizhi, M.Vijayalakshmi, Bulk growth and characterization of novel organic Piperazinium (bis) hydrogen succinate single crystals, J. Cryst. Growth. 452 (2016) 204-212. [40] N. Vijayan, G. Bhagavannarayana, R. Ramesh Babu, R. Gopalakrishnan, K.K. Maurya, P.Ramasamy, Cryst. Growth Des 6(2006)1542-1546.

[41] N.Sonia, M.Vijayan, P.Vij, B.Kumar, S.Singh, Das, Rajnikant, H.Soumya, Mater. Chem. Front 1 (2017) 1107-1117

[42] M.Sheik-Bahae, A.A.Said, Tai-Huie Wei, David J.Hagan, E.W.Van Stryland, Sensitive measurement of optical nonlinearities using a single beam, IEEE J. Quantum Electron. 26 (1990) 760-769.

[43] M.Sheik-Bahae, D.C.Hutchings, D.J.Hagan, E.W. Van Stryland, Dispersion of bound electron nonlinear refraction in solids , IEEE J. Quantum Electron. 27 (1991)1296-1309. [44] P.Vivek, A.Suvitha, P.Murugakoothan, Growth, spectral, anisotropic, Second and third order nonlinear optical studies on potential nonlinear optical crystal anilinium perchlorate (AP) for NLO device fabrications, spectrochim. Acta A, 134 (2015) 517-525.

[45] Yun Shan Zhou, En Bo Wang, Jung Peng, Jie Liu, Chang wen, Ru dan Huang, Xiaozeng you, Synthesis and the third-order optical nonlinearities of two novel charge-transfer complexes of a heteropoly blue type $\left(\mathrm{C}_{9} \mathrm{H}_{7} \mathrm{NO}\right)_{4} \mathrm{H}_{7} \mathrm{PMo}_{12} \mathrm{O}_{40} \cdot 3 \mathrm{H}_{2} \mathrm{O}\left(\mathrm{C}_{9} \mathrm{H}_{7} \mathrm{NO}=\right.$ quinolin-8-ol $)$ and (phen $)_{3}$ $\mathrm{H}_{7} \mathrm{PMo}_{12} \mathrm{O}_{40} . \mathrm{CH}_{3} \mathrm{CN} . \mathrm{H}_{2} \mathrm{O}$ (phen= 1,10-phenanthroline), Polyhedron 18 (1999) 1419-1423.

[46] N.J.Dovichi, J.M.Harris, Laser induced thermal lens effect for calorimetric trace analysis, Anal. Chem. 51 (1979) 728-731.

[47] S.Leela, K.Ramamurthi, G.Bhagavannarayana, Synthesis, growth, spectral, thermal, mechanical and optical properties of 4-chloro-4'dimethylamino- benzylidene aniline crystal: A third order nonlinear optical material, Spectrochim. Acta A 74 (2009) 78-83.

[48] R.Santhakumari, K.Ramamurthi, Structural, thermal and optical characterization of an organic NLO material- Benzaldehyde thiosemicarbazone monohydrate single crystals, Spectrochim. Acta A 78 (2011) 653-659. 
Highlights:

$>\mathrm{PzZrOCl}$ crystalline perfection is reasonably good with UV cut off $215 \mathrm{~nm}$.

$>$ Crystals show $98 \%$ transparency with Green emission at $545 \mathrm{~nm}(2.27 \mathrm{eV})$.

$>$ Thermal stability is $169^{\circ} \mathrm{C}$ and LID tolerance is $0.6 \mathrm{GW} / \mathrm{cm}^{2}$.

$>$ The crystals show RISE behavior with $n$ value 3.31 (soft category).

$>$ Self-defocusing nature is observed with TPA phenomenon. 
Figures

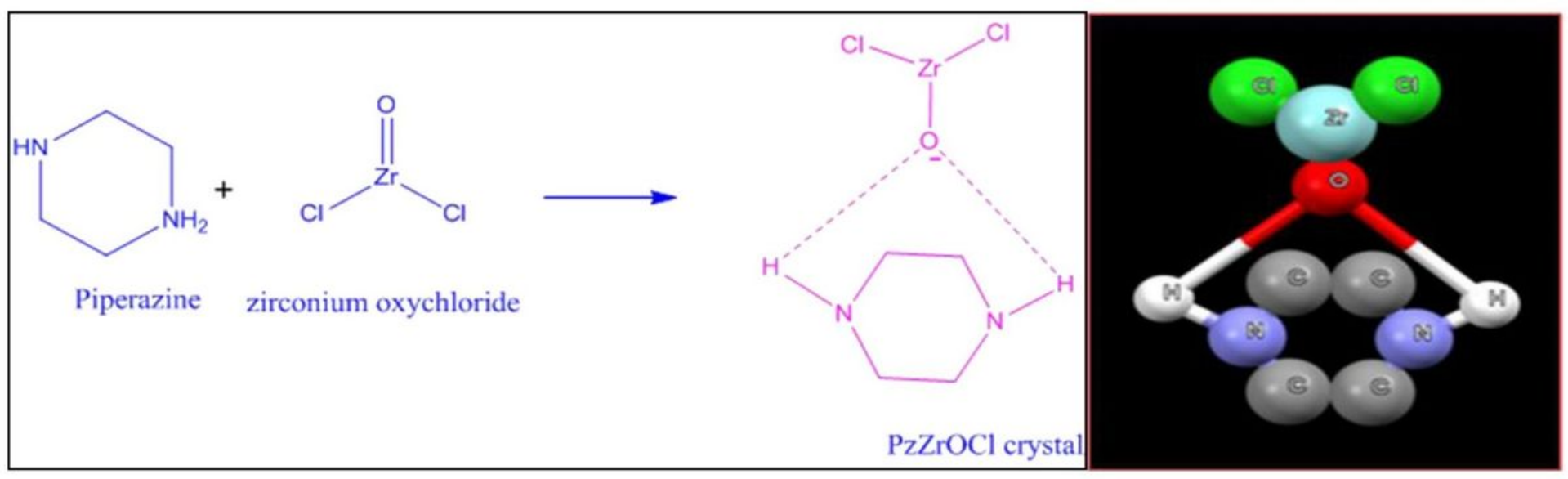

Figure 1

Scheme of synthesis for PzZrOCl single crystals.

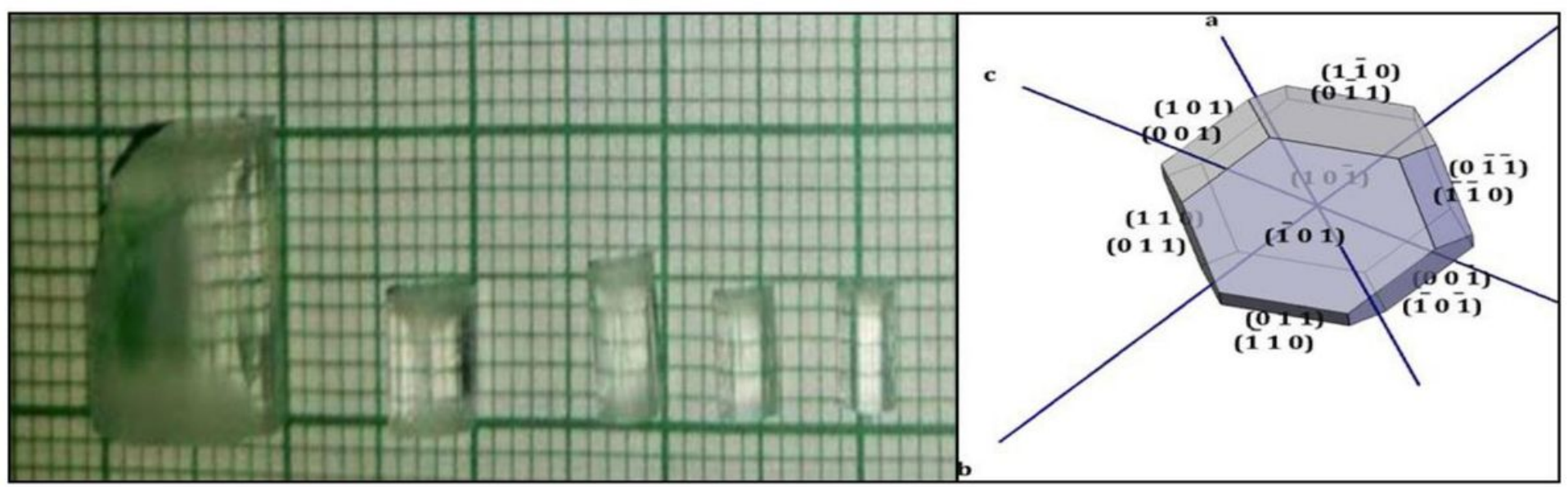

Figure 2

Photograph and crystal habits of PzZrOCl single crystals. 


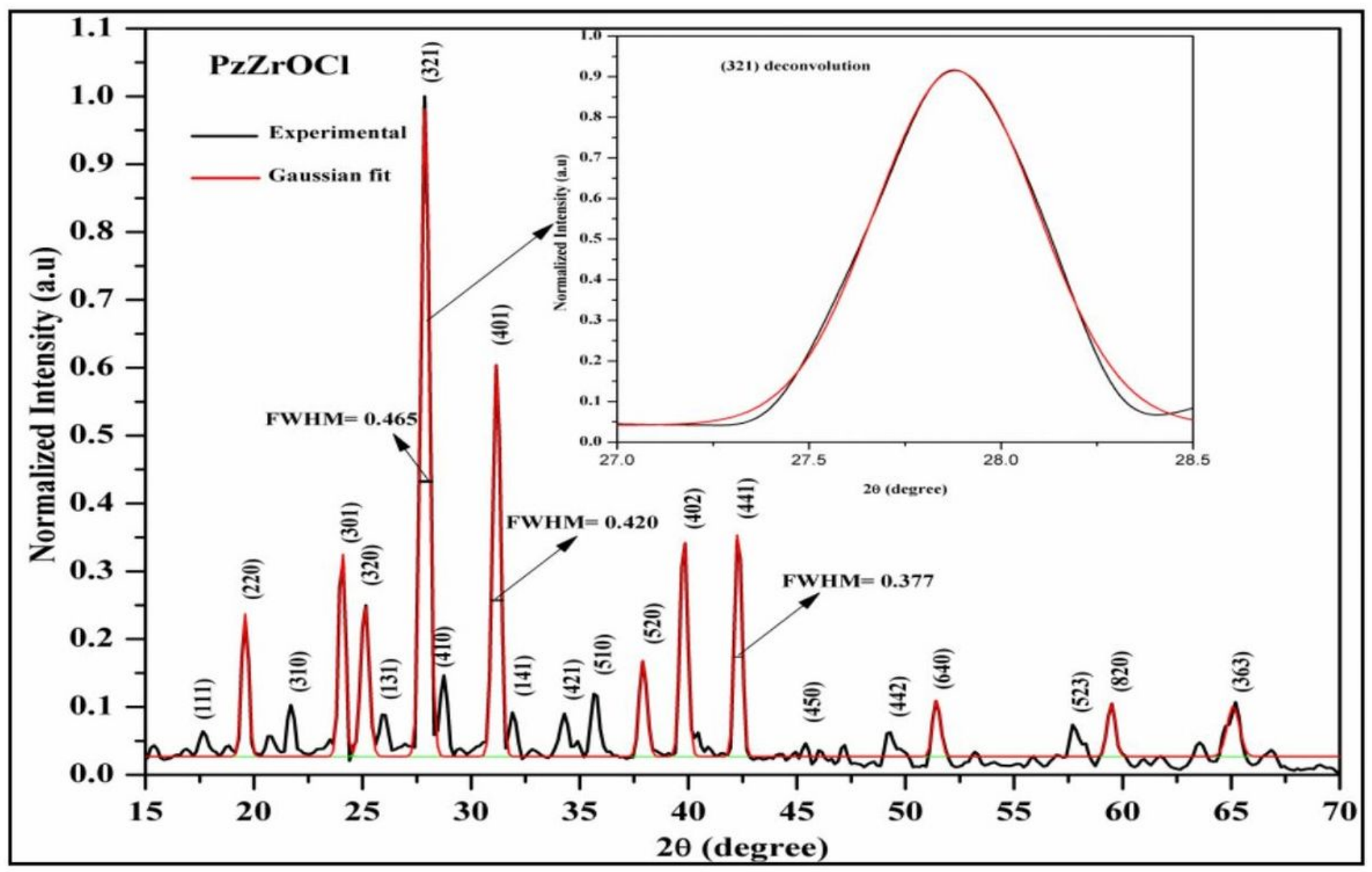

Figure 3

Powder X-ray diffraction pattern of PzZrOCl single crystals. 


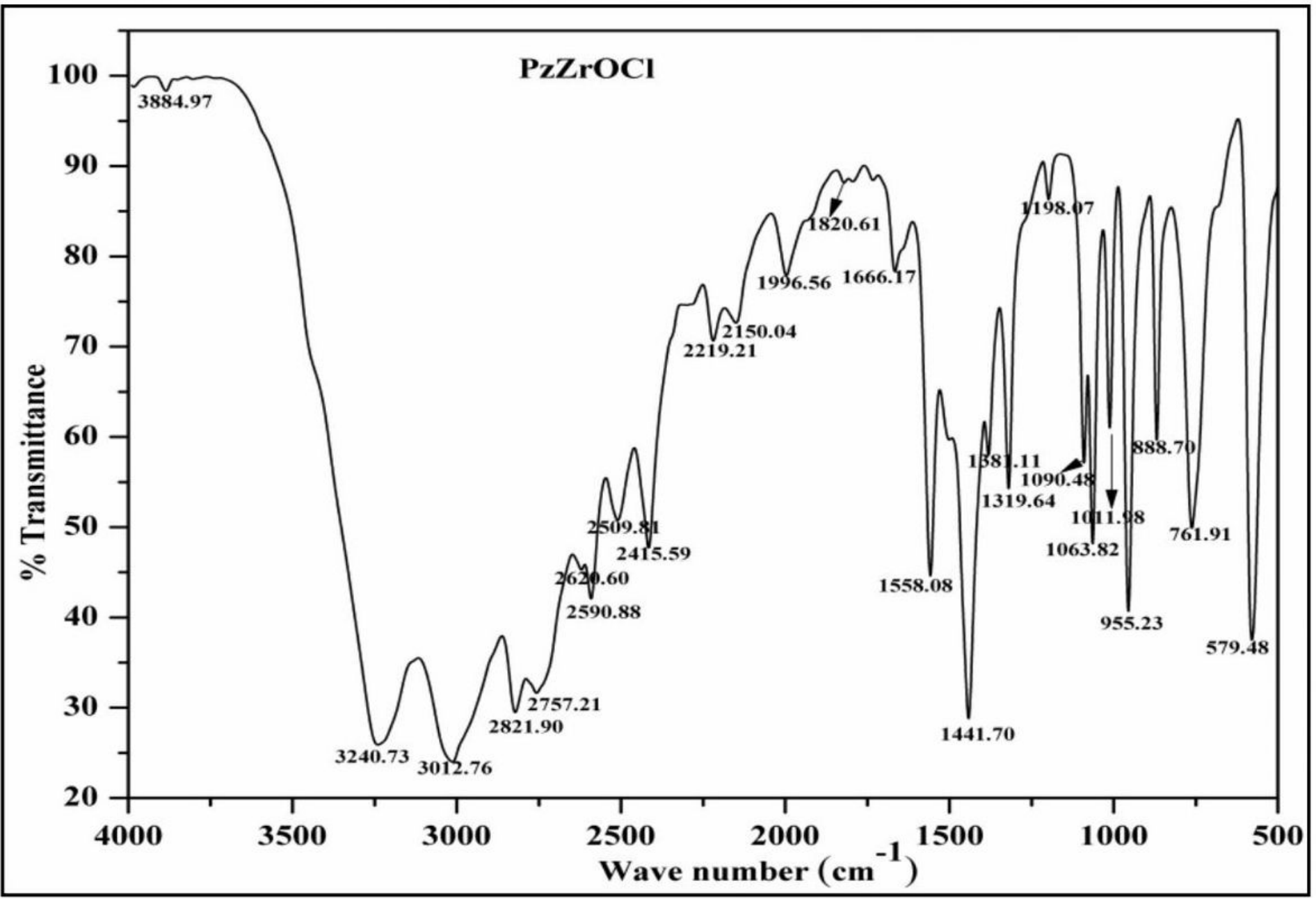

Figure 4

FT-IR spectrum of PzZrOCl single crystals. 


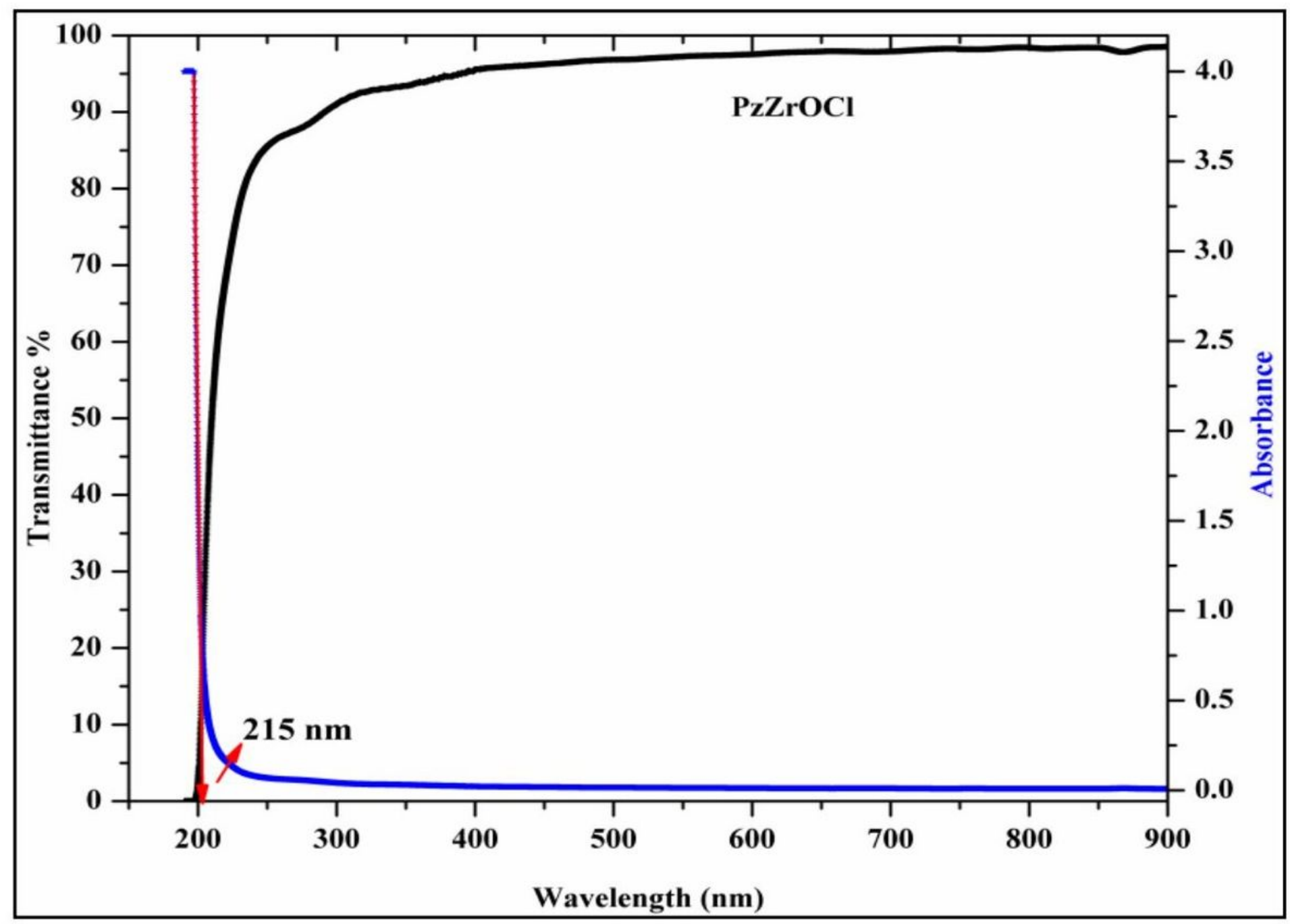

Figure 5

UV-vis-NIR spectrum of PzZrOCl single crystals. 


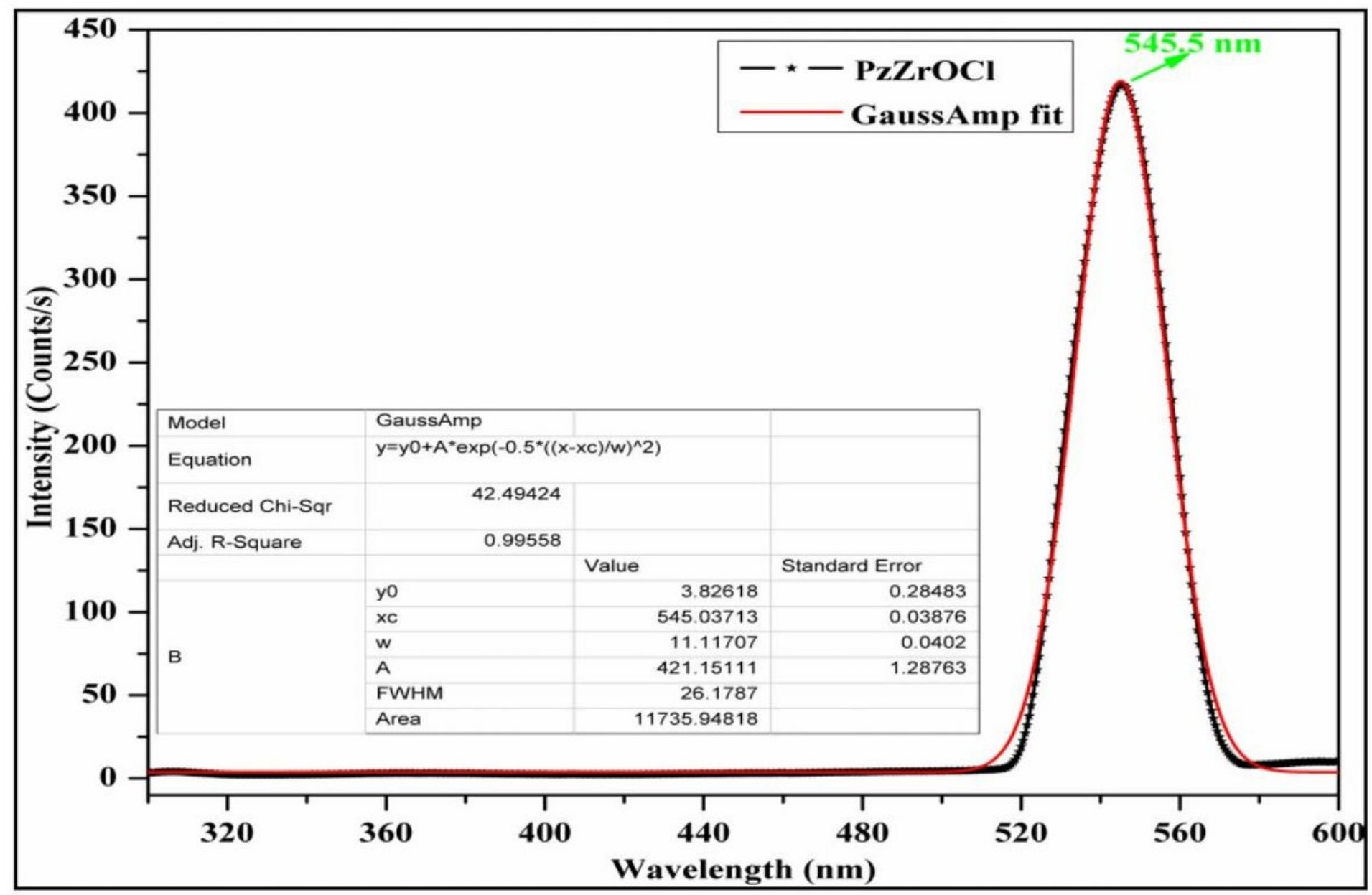

Figure 6

Photoluminescence spectrum of PzZrOCl single crystals.

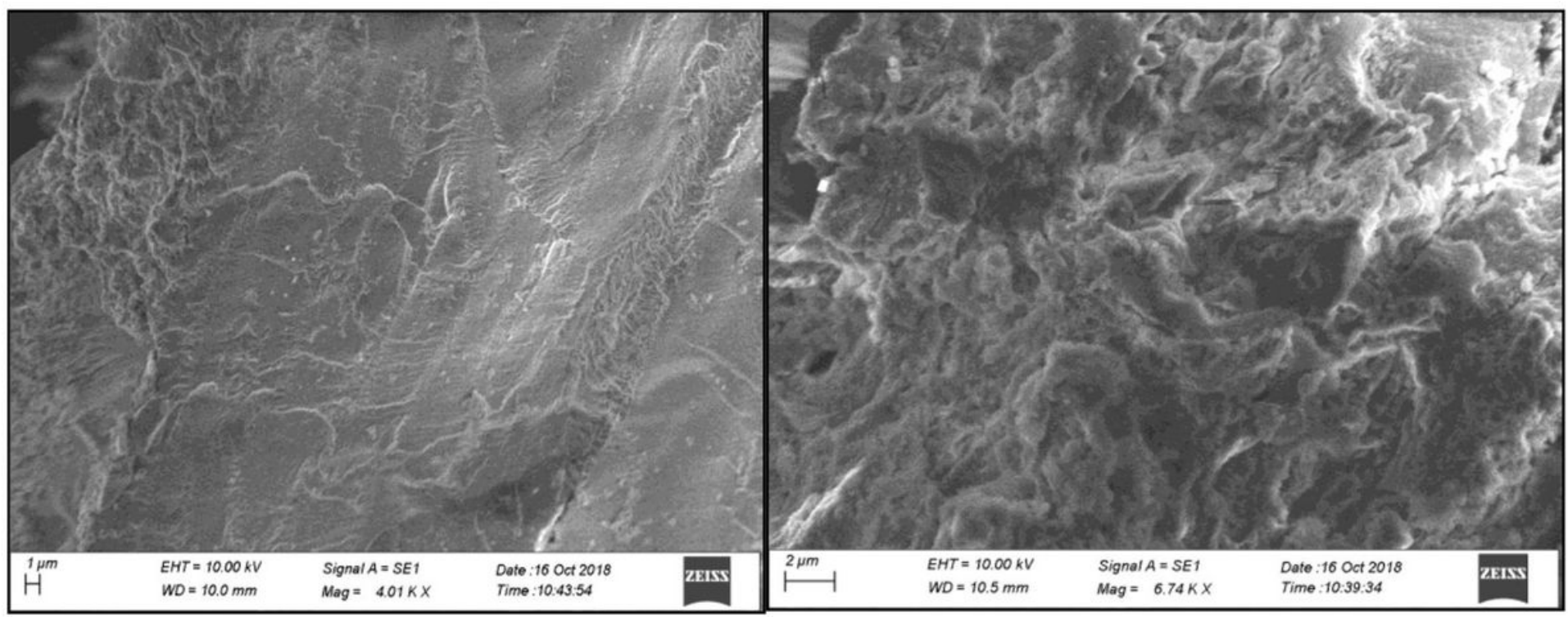

Figure 7 
SEM images of as grown PzZrOCl single crystals.

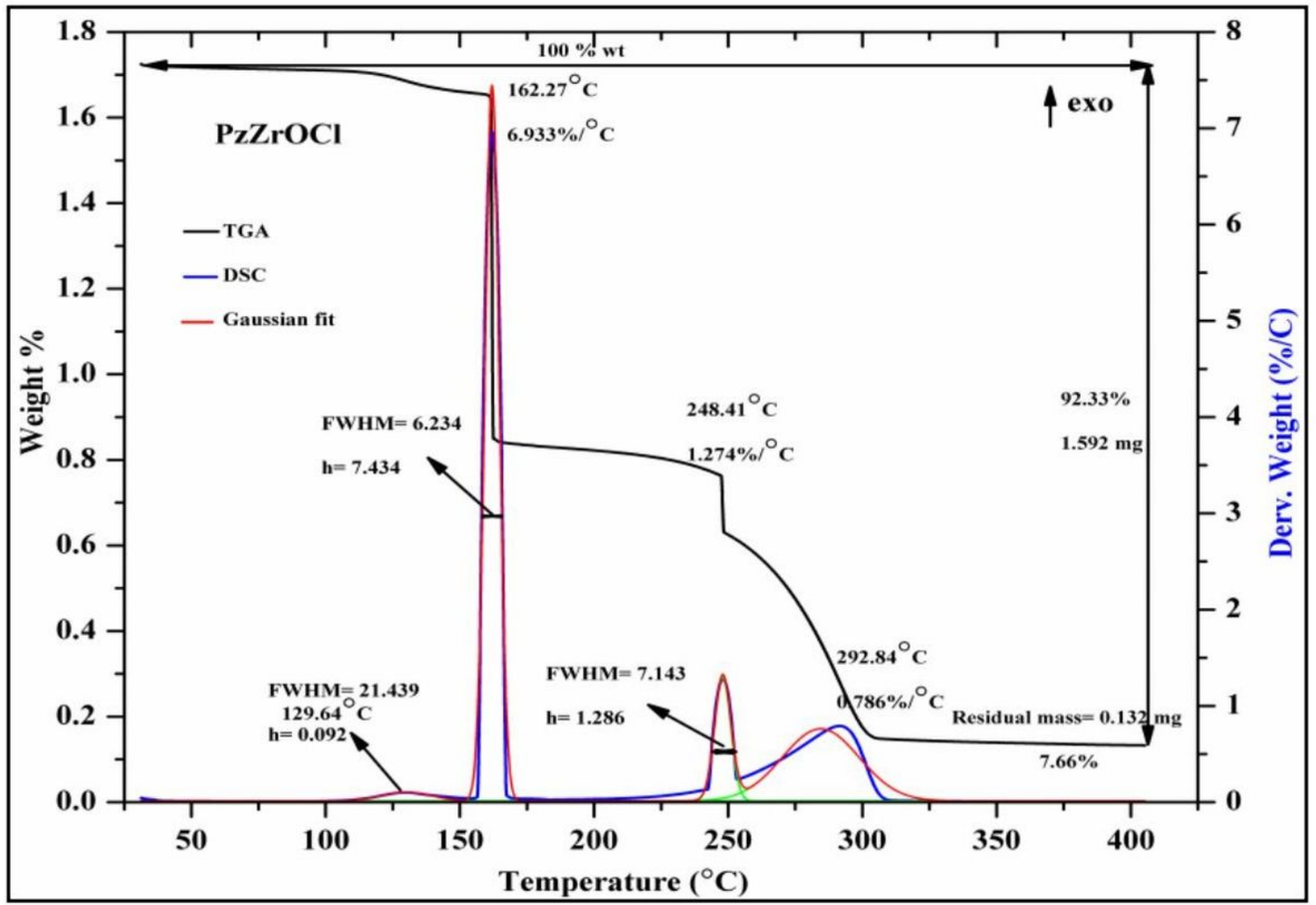

Figure 8

TG/DTA curves of PzZrOCl single crystals. 


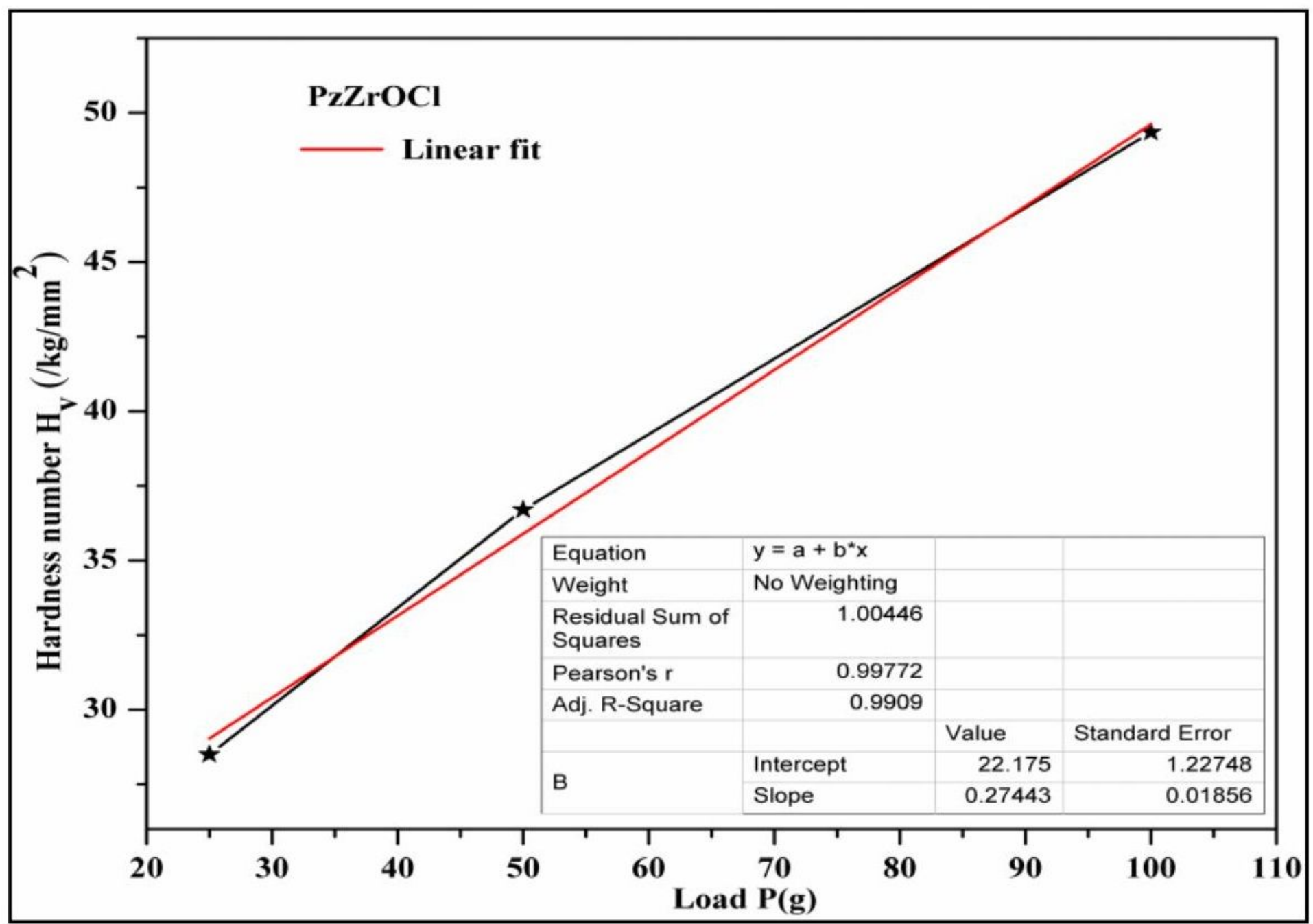

Figure 9

Plot of microhardness vs. load for PzZrOCl single crystals. 


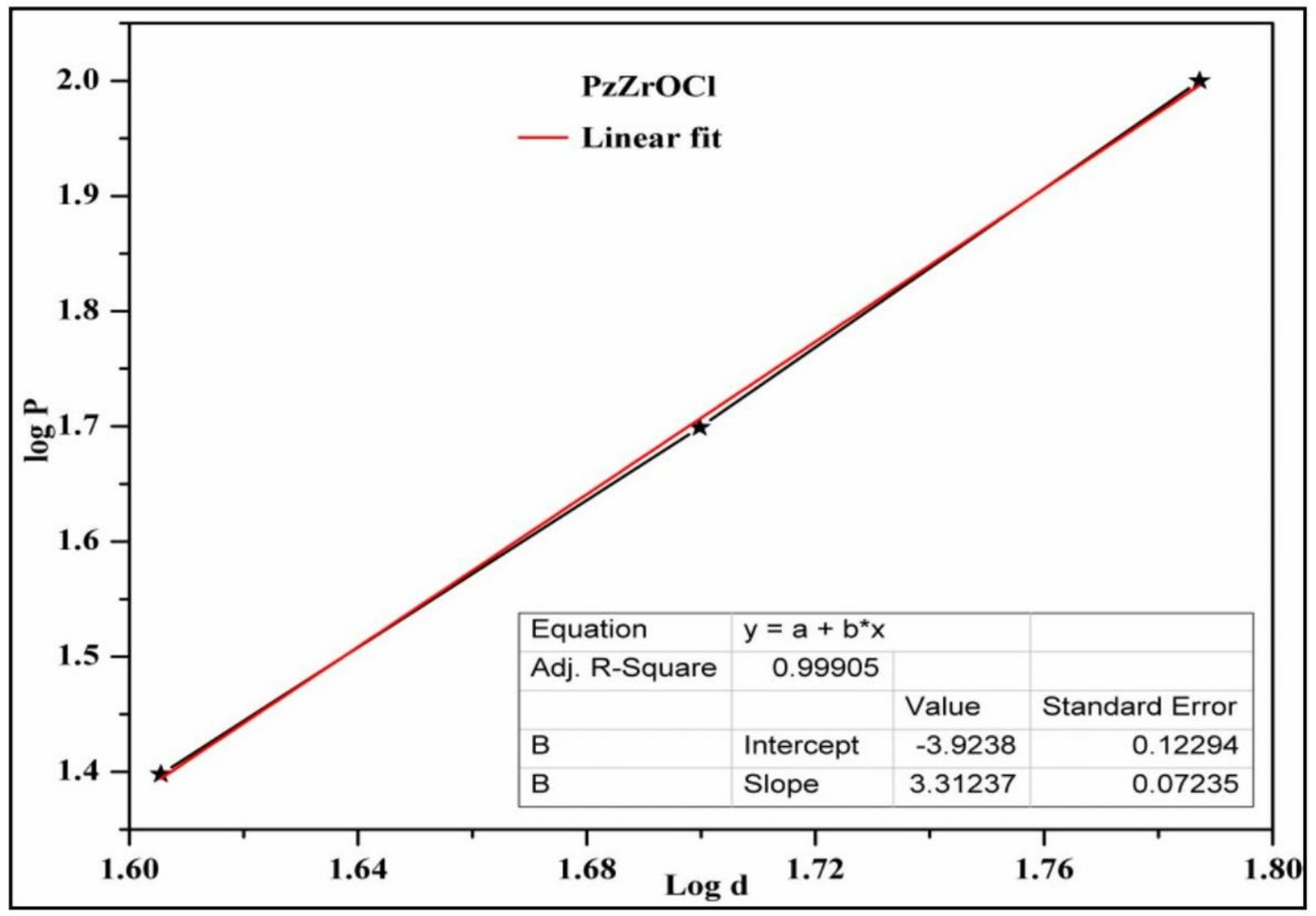

Figure 10

Plot of log P vs. log d for PzZrOCl single crystals. 


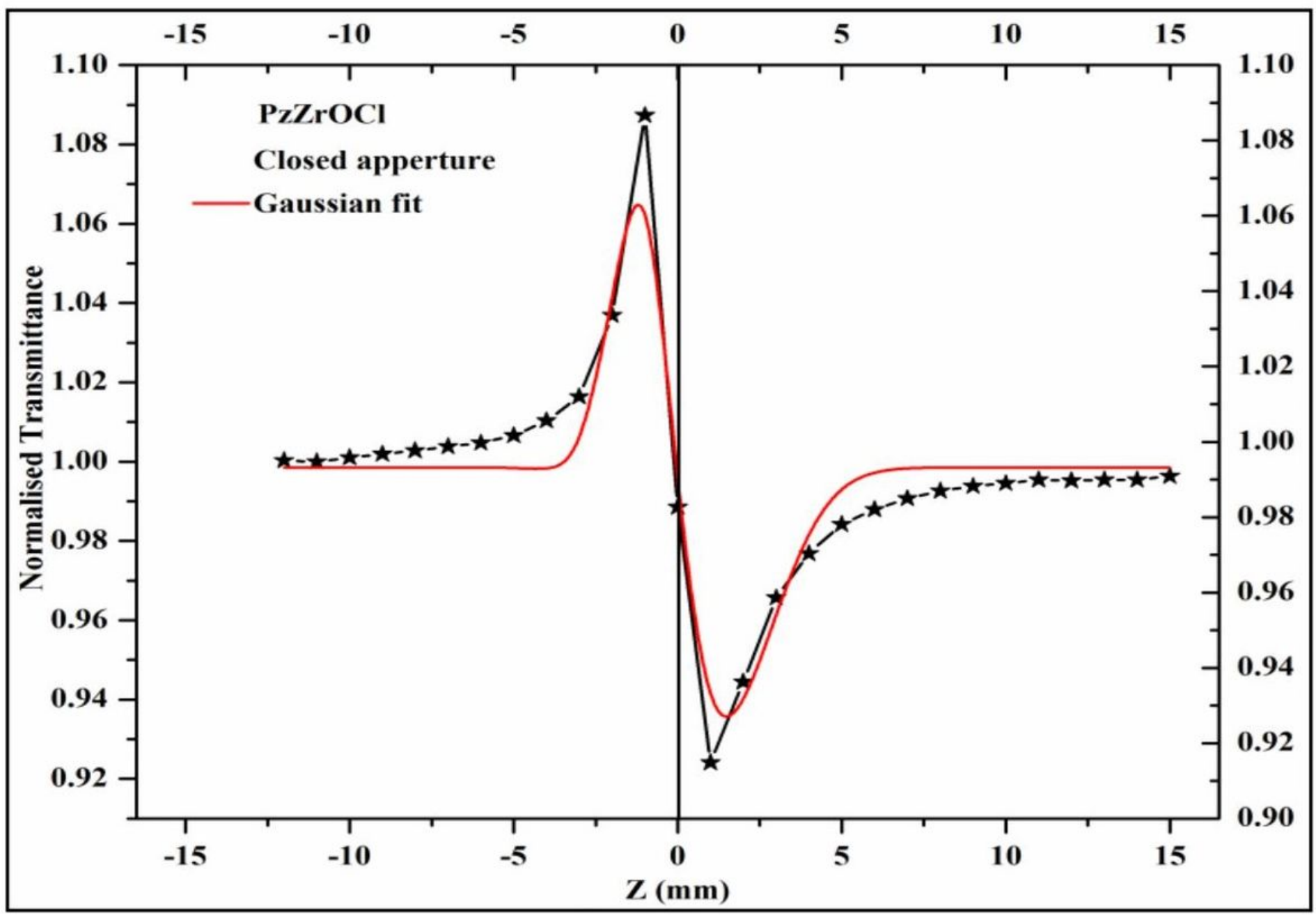

Figure 11

Z-scan closed aperture for PzZrOCl single crystals. 


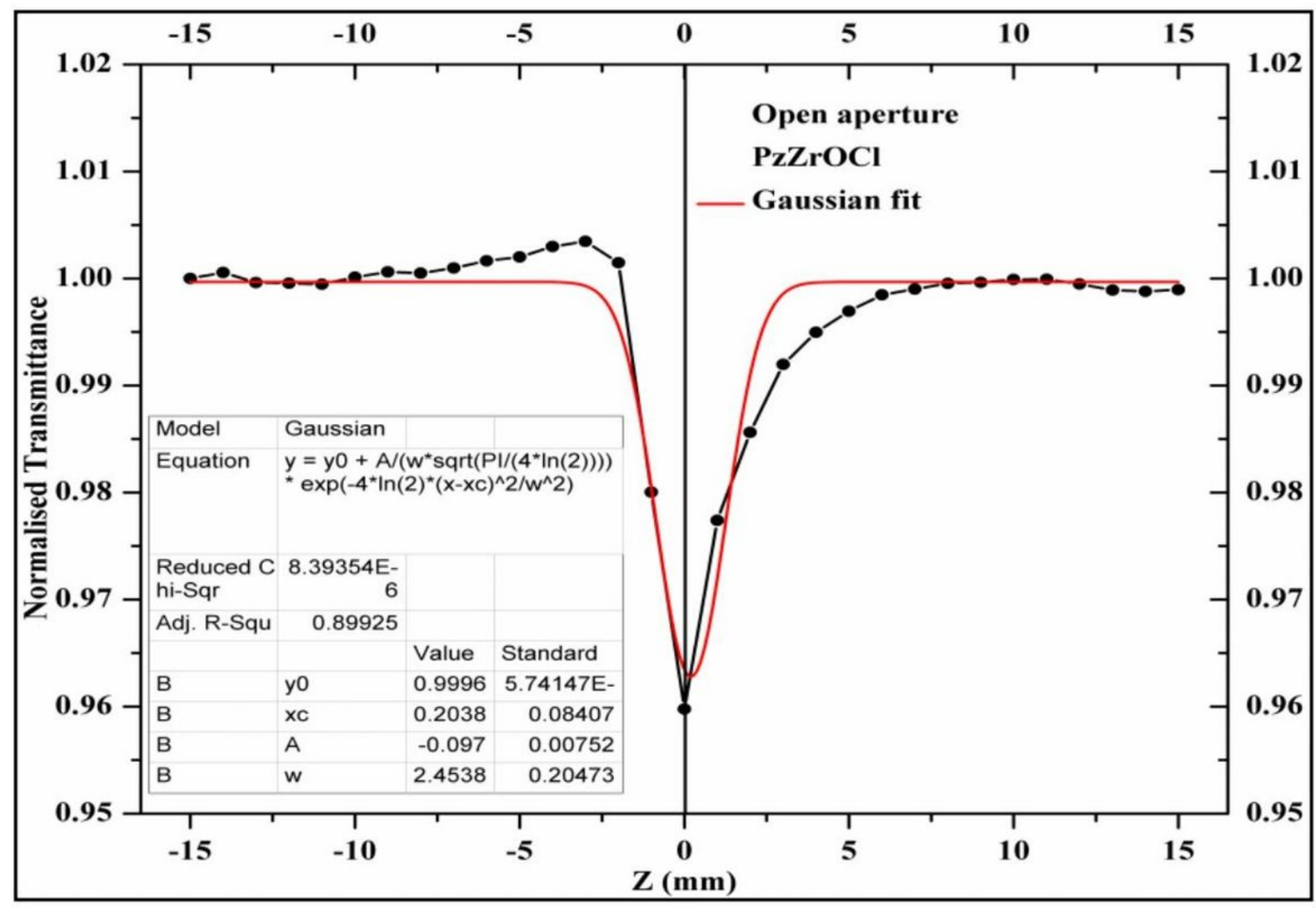

Figure 12

Z-scan open aperture for PzZrOCl single crystals. 


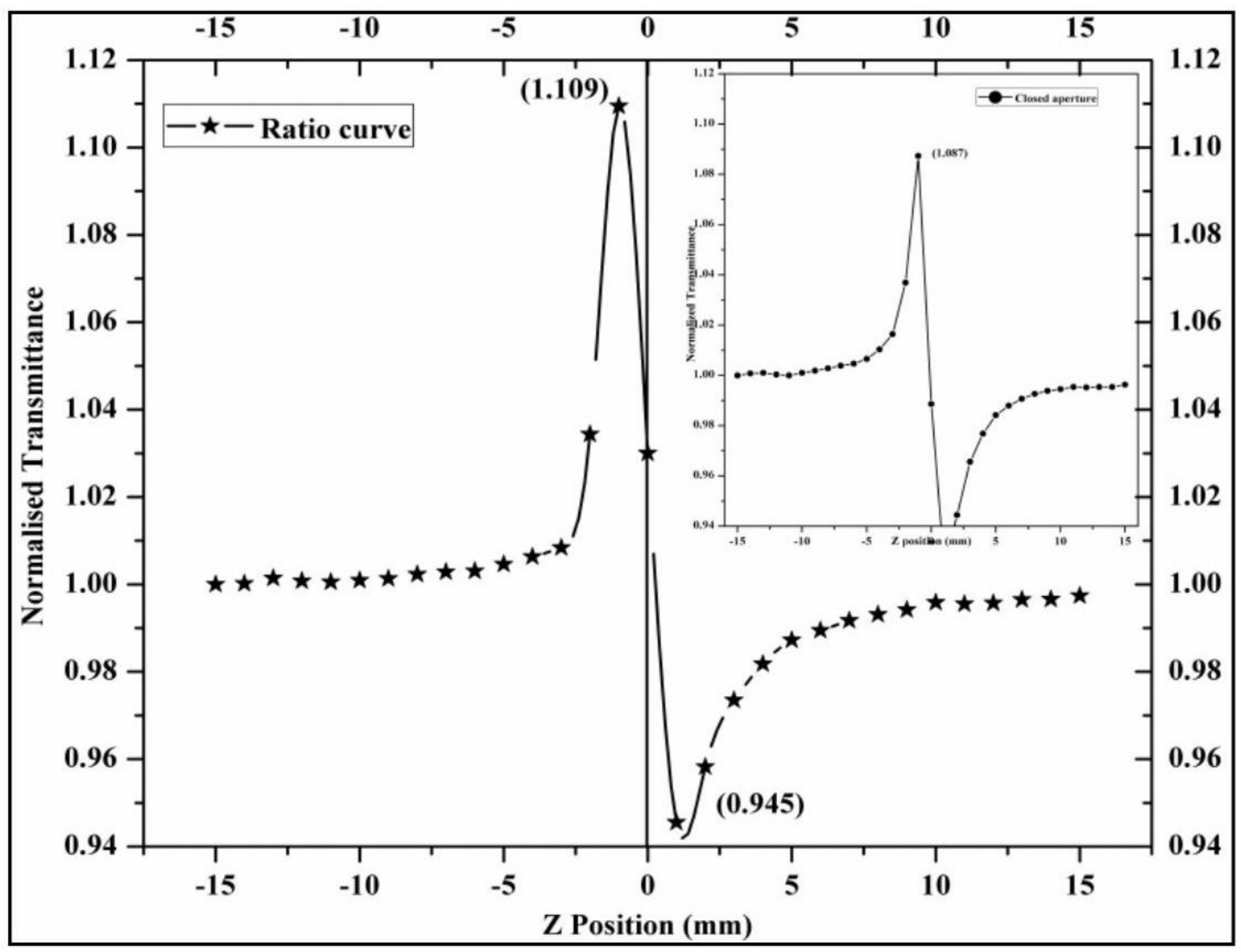

Figure 13

Z-scan ratio curve for PzZrOCl single crystals

\section{Supplementary Files}

This is a list of supplementary files associated with this preprint. Click to download.

- Table1.docx 